\title{
Exegese Iconográfica: uma brevíssima introdução
}

\section{Iconographic Exegesis: a very short introduction}

\section{Exégesis Iconográfica: una breve introducción}

\author{
Prof. Dr. Silas Klein Cardoso* \\ Submetido em: 1-3-2021
}

Aceito em: 22-4-2021

\author{
* Universität Bern; Universität Zürich \\ silasklein@gmail.com
}

\begin{abstract}
RESUMO
Exegese Iconográfica é uma perspectiva dentre os Estudos Bíblicos que utiliza vestígios visuais da antiga Palestina/Israel para iluminar termos, textos ou conceitos bíblicos. Enquanto suas origens remontam a Othmar Keel e pesquisadores associados a ele - a chamada Escola de Friburgo -, sua prática alcançou recentemente posição consolidada dentre o cânon de perspectivas exegéticas. Contudo, apesar de ser praticada há quase cinquenta anos no mundo germanófono e pouco mais de trinta anos no mundo anglófono, pouco se produziu sobre a perspectiva em língua portuguesa. $O$ artigo preenche essa lacuna, fazendo uma brevíssima introdução à perspectiva, apresentando sua definição, desenvolvimentos históricos, principais conceitos e métodos.

Palavras-chave: Exegese iconográfica; exegese bíblica; Bíblia Hebraica/Antigo Testamento; Novo Testamento; Métodos de interpretação bíblica.
\end{abstract}

\begin{abstract}
Iconographic Exegesis is a perspective within Biblical Studies that uses visual remains of ancient Palestine/Israel to illuminate biblical terms, texts, or concepts. Its origins go back to Othmar Keel and his associated researchers, the so-called Freiburg School, and its practice has recently reached a consolidated position among the canon of exegetical perspectives. However, despite being practiced for almost fifty years in the German-speaking world and just over thirty years in the English-speaking world, little has been produced about the perspective in Portuguese. The article fills this gap by making a very brief introduction to perspective, presenting its definition, historical developments, main concepts and methods. Keywords: Iconographic exegesis; biblical exegesis; Hebrew Bible/Old Testament; New Testament; biblical interpretation methods.
\end{abstract}

\section{RESUMEN}

La exégesis iconográfica es una perspectiva dentro de los estudios bíblicos que utiliza restos visuales de la antigua Palestina/Israel para iluminar términos, textos o conceptos bíblicos. Sus orígenes se remontan a Othmar Keel y sus investigadores asociados, la llamada Escuela de Friburgo, y su práctica ha alcanzado recientemente una posición consolidada entre el canon de las perspectivas exegéticas. Sin embargo, a pesar de que se practica desde hace casi cincuenta años en el mundo de habla alemana y algo más de treinta años en el mundo de habla inglesa, poco se ha producido sobre la perspectiva en portugués. El artículo llena este vacío haciendo una brevísima introducción a la perspectiva, presentando su definición, evolución histórica, principales conceptos y métodos.

Palabras clave: Exégesis iconográfica; exégesis bíblica; Biblia hebrea/Antiguo Testamento; Nuevo Testamento; métodos de interpretación bíblica. 


\section{Introdução}

O tema deste dossiê, "revisitando a Bíblia a partir de perspectivas modernas", nos convida não apenas a pensar sobre as possíveis abordagens e metodologias empregadas no estudo da Bíblia Hebraica/Antigo Testamento $(\mathrm{BH} / \mathrm{AT})$ e/ou do Novo Testamento (NT). Ele é, também, um convite à reflexão sobre quais seriam os fundamentos e limites da disciplina chamada Estudos Bíblicos (Biblical Studies) ou Ciências Bíblicas (Bibelwissenschaften), assim como sobre quais as competências requeridas para o estudo da Bíblia na atualidade. Embora dominante, é reducionista a visão que pensa a disciplina como o estudo de textos canônicos em seus sentidos originários. ${ }^{1}$ Talvez, em seus princípios, como herdeira da philologia sacra moderna, ou, mais recentemente, nos círculos de filólogos e teólogos protestantes europeus, ${ }^{2}$ a disciplina tenha tido tal enfoque. Hoje, porém, ela se ocupa desde os fatores que desencadearam, possibilitaram e interagiram com os textos bíblicos, até com os impactos desses textos em diversas sociedades no decorrer do tempo e do espaço. Nisso, além das inevitáveis sub-especializações, uma série de novas habilidades passaram a ser desejáveis para estudiosos e estudiosas da Bíblia. Um fenômeno relativamente recente é o da interpretação científica de imagens em prol da compreensão de textos bíblicos.

A perspectiva chamada Exegese Iconográfica (EI) oferece uma nova via de acesso ao contexto histórico-cultural dos textos bíblicos e se transformou, nos últimos trinta anos, num importante player dentre os Estudos Bíblicos. Como principais contribuições, a perspectiva ajuda a preencher a lacuna entre palavras ancestrais e imagens mentais, assim como coopera à visualização

1 Refiro-me à tendência, até os anos 1960, nos estudos da BH/AT, de pensar que "o método-histórico crítico era a única forma 'respeitável' de lidar com o texto” (ROGERSON, 2006, p. 15, tradução minha). Apesar de desenvolvimentos distintos, os métodos de orientação histórico-crítica também imperavam até 1980 na exegese do NT. Isso, obviamente, não significa a falta de uso de outras fontes como, p.ex., achados arqueológicos. Entretanto, o uso desses achados era distinto, como se pode observar no uso crítico e filiado à hipótese documentária de Albrecht Alt e Martin Noth, na escola alemã, e na oposição da escola americana de William M. Albright.

2 Tal aspecto, vale notar, também foi presente na interpretação acadêmica judaica. No contexto protestante, o ápice se deu no século 17, quando teólogos reformados passaram a considerar que "filologia não é uma ciência auxiliar da Teologia, mas Teologia é ciência filológica - é philologia sacra" (STEIGER, 2008, p. 727, tradução minha). O aspecto estava ligado à visão protestante sobre a perfeição e suficiência das Escrituras, enquanto a interpretação católica igualava a Escritura à Tradição. Tal tendência católica foi alterada entre os séculos 19 e 20, principalmente a partir da encíclica Divino Afflante Spiritu em 1943 e, antes, com outros movimentos, do qual destaco a fundação da École Biblique et Archéologique Française de Jérusalem, em 1890, pelo exegeta dominicano Marie-Joseph Lagrange. Tais desenvolvimentos permitiram a inserção dos métodos histórico-críticos na interpretação bíblica de tradição católica que, a partir disso, passaram a rivalizar o espaço até então exclusivamente protestante e judaico (FITZMYER, 2008; FLYNN 2020, p. 29-35). 
de práticas omitidas ou interditadas no registro bíblico. Muitos exemplos podem ser dados. Antes incompreensível, o discurso de Javé em Jó 38-41 é hoje acessível via comparação com o motivo "senhor dos animais" ou de Hórus lutando contra o hipopótamo ou crocodilo (KEEL, 1978b; cf. NEUMANN-GORSOLKE, 2012; KLEIN CARDOSO, 2020a, p. 152-153; fig. 1a-b). A esquiva figuração dos serafins em Is 6.1-8 é hoje compreendida via comparação à serpente alada egípcia (ureu) (KEEL, 1977a, p. 70-124; fig. 1c), enquanto querubins são compreendidos através da comparação às criaturas mistas aladas que ou portam-se como assentos para a divindade (cf. KEEL, 1977a, p. 15-45; METZGER, 1985; fig. 1c) ou guardam a fronteira entre céus e terra, entre sagrado e profano (STAUBLI, 2012, p. 55). ${ }^{3}$ A linguagem metafórica de Salmos (BS), de Cantares (KEEL, 1984; 1986b) e Provérbios (KEEL, 1974a), assim como descrições de deuses e deusas (KLINGBEIL, 1999; LEMON, 2010) também estão ao alcance da imaginação, graças ao conhecimento de antigos regimes visuais.

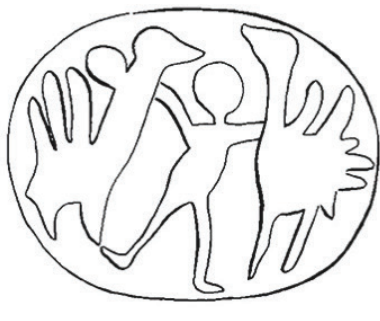

(a)

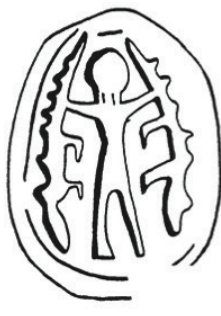

(b)

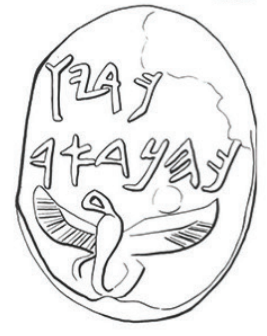

(c)

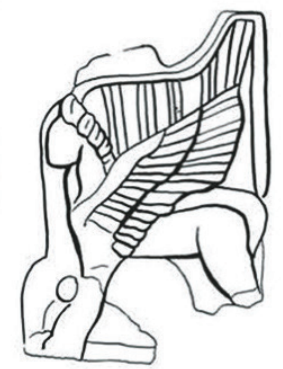

(d)

Figura 1

Fonte: (a) selo de Nasbeh com imagem de figura antropomórfica entre duas aves bípedes, provavelmente avestruzes (KEEL, 1978b, p. 104, n. 39); (b) selo de Tell el-'agūl com imagem antropomórfica com duas figuras laterais, provavelmente Crocodilos (SSPI III, p. 342, n. 11; = CSAP I, p. 170-170, n. 200); (c) selo de Dor com inscrição “lșdq bnmk', "pertecente a Sadoq filho de Mikah" e ureu alado (KEEL, 1977a, p. 104, n. 87); (d) marfim de Meggido com um trono de querubim (KEEL, 1977a, p. 20, n. 6).

Na História da Religião de Israel, a EI foi fundamental ao trazer uma nova compreensão e uso de imagens enquanto fontes (TOORN, 1997; DEVER, 2005), além de fornecer convincente argumentação de que "havia imagens em Israel" (SCHROER, 1987). Isso permitiu novos passos, como a diferenciação regional de iconografias divinas (GGG, p. 191-194; KLEIN CARDOSO, 2020b, p. 28-34) e a percepção do feminino na história da reli-

\footnotetext{
3 A partir desse pano de fundo, e com a junção tardia à figuração de Nice, construíram a concepção de "anjos" do Período do Segundo Templo (KEEL, 2010a; cf., recentemente, HULSTER, 2015).
} 
gião da região. Assim, ela teve papel central, p.ex., tanto na discussão sobre Asherá (FREVEL, 1995; KEEL, 1998b) e no traçado dos diferentes perfis femininos de divindades (WINTER, 1987; CORNELIUS, 2008; UEHLINGER, 2019; cf. KEEL; SCHROER, 2004; SCHROER, 2008b), quanto na discussão sobre o interdito de imagens (cf. TOORN, 1997; UEHLINGER, 2019a).

No presente estudo, faço uma brevíssima introdução à EI, apresentando sua definição, desenvolvimentos históricos, principais pressupostos e correntes práticas. Longe de ser exaustivo, meu estudo pretende iniciar o diálogo e inserir a perspectiva no campo bíblico brasileiro e lusófono. Isso se faz necessário pela falta de material produzido em língua portuguesa e, também, pela desatualização da última - e, até onde sei, única - introdução à perspectiva no Brasil (KLEIN CARDOSO, 2017). Embora existam materiais traduzidos à língua portuguesa (SCHROER, 1994; KEEL, 1995; UEHLINGER, 1995; 2019b; SCB) e, recentemente, materiais produzidos no Brasil que partiram da perspectiva (KLEIN CARDOSO, 2019; 2020c; SOUZA, 2019), não foi encontrada introdução ao tópico.

\section{Por uma definição de Exegese Iconográfica}

Terminologicamente, há diferentes formas de se referir à perspectiva. ${ }^{4}$ Enquanto alguns simplesmente utilizam, no contexto dos Estudos Bíblicos, Iconografia (Iconography; p.ex., CORNELIUS, 2013) e de já ter sido chamada Bíblia e Iconografia (Bibel und Ikonographie; KEEL, 1985a), há, hoje, dois termos preponderantes: (1) Exegese Iconográfica, no mundo anglófono (Iconographic Exegesis; p.ex., HULSTER 2009a; IEHBOT); e (2) Iconografia Bíblica ou Iconografia da Palestina no mundo germanófono (Biblische Ikonographie, SCHROER, 1995; Ikonographie Palästinas, BERLEJUNG, 2019)..$^{5}$ Por conveniência, uso o termo corrente nos círculos internacionais, Exegese Iconográfica. O termo, que enxergo como guarda-chuva para diversas abordagens, advém da junção do nome de dois métodos de investigação, um focado na interpretação de textos

\footnotetext{
4 Há divergência quanto à caracterização de EI. Ela já foi chamada "virada filosófica parcial [sic]" (BONFIGLIO, 2016, p. 1-5), perspectiva (CORNELIUS, 2013, p. 784), aproximação (HULSTER, 2008; IEHBOT, p. 20), método (TÖYRÄÄNVUORI, 2020, p. 51) e disciplina (KLINGBEIL, 1999, p. 8).

5 Note que o adjetivo "bíblica" da tradição alemã usa a mesma lógica de disciplinas correlatas, em especial Biblischen Archäologie / Archäologie Palästinas (Arqueologia Bíblica/Arqueologia da Palestina). Contudo, note que o uso por Angelika Berlejung (2019) difere da definição clássica dada pela primeira vez por Silvia Schroer (1995 [1992], p. 220; avançando a proposta de KEEL, 1985a). Enquanto Berlejung define a iconografia como um estudo independente, mas focalizado no contexto cultural do antigo Israel, a definição de Schroer enfatiza o aspecto comparativo entre textos bíblicos $e$ imagens de seu tempo de produção.
} 
("exegese") e outro focado na interpretação de imagens ("iconografia"). Assim, juntos, eles revelam a natureza comparativa da perspectiva, esta que se dá em dois processos geralmente paralelos, mas independentes.

Três definições de EI são relevantes nesse contexto. A primeira vem do fundador da perspectiva, Othmar Keel (1985a, p. 143, tradução minha), que definiu Bibel und Ikonographie (Bíblia e Iconografia) como "o relacionamento entre textos bíblicos e sua arte contemporânea [i.e., contemporânea aos textos]". Izaak de Hulster (2011, tradução minha), por sua vez, definiu IE como "um passo na interpretação textual que deve ser localizado dentro dos métodos da interpretação histórico-crítica da Bíblia”. Mais recentemente, Hulster, Strawn e Bonfiglio (IEHBOT, p. 20, tradução minha), no primeiro e, até o momento, único manual oferecido exclusivamente à perspectiva, a definem como "abordagem interpretativa que explica aspectos da Bíblia Hebraica com a ajuda de vestígios visuais do antigo Oriente Próximo".

Cada definição marca um momento distinto na história intelectual da EI. Keel e Hulster enfatizaram sua orientação histórica. Quando Keel abordou o tema nos anos 1980, não havia clareza quanto aos procedimentos e enquadramento na disciplina Estudos Bíblicos. Dessa forma, ele procurou distingui-la das novas leituras com foco no leitor que emergiam à época, ${ }^{7}$ assim como da ilustração edificante de textos bíblicos (cf. SCHROER, 1995, p. 220). Hulster, por sua vez, tratou o tema quando os resultados da prática eram bem aceitos (esp. após KEEL, 1977a; 1978b; GGG), mas sua integração à exegese não era evidente. No contexto, ele tentou legitimar a prática dentre a exegese histórico-crítica tradicional, a caracterizando como passo da exegese histórico-crítica. ${ }^{8}$ A terceira definição marca o passo rumo à institucionalização de EI. Por um lado, isso implica na problemática restrição à BH/AT e ao AOP. ${ }^{9}$ Por outro lado, EI não é mais vista como exclusivamente subordinada a um

6 Chamo atenção ao fato de que o termo pode fazer referência a (1) um método de análise que descreve imagens (gr. eikenèe+grăphè), (2) um quadro conceitual de estudos culturais ou (3) fontes visuais, propriamente ditas.

7 Que hoje são chamados "estética da recepção" ou, ao tratar recepção nas artes visuais, "exegese visual” ou "crítica visual” (Visual Exegesis; Visual Criticism; cf. EXUM, 2019, p. 4-5).

8 Comparar a definição de Hulster em sua tese doutoral (2008, p. 369), na versão publicada (2009a, p. 102) e, dois anos depois, na enciclopédia virtual WibiLex (2011) é elucidativo sobre essa mudança de contextos.

9 Embora disciplinarmente a restrição se justifique, há uma série de problemas. Sócio-epistemologicamente, há uma tradição interpretativa ligada ao NT que deve ser considerada (p.ex., KÜCHLER, 1986; 1987; THEISSEN, 1989; GEMÜNDEN, 1993; WEISSENRIEDER; WENDT; GEMÜNDEN, 2005). Historicamente, além do fato do conceito de cânon ser incerto, tradições culturais não respeitam limites canônicos. Isso é verdade em textos e imagens, que não se limitam ao chamado "período israelita". Pelo contrário, certas tradições estão presentes desde o período neolítico até o bizantino, enquanto outras são localizadas, algo já demonstrado convincentemente (cf. IPIAO I-IV; SCHROER; WYSSMANN, 2019). 
método textual (i.e., histórico-crítico) e reconhecem-se múltiplas abordagens (cf. WEISSENRIEDER; WENDT, 2005). Nisso, tanto o uso de "vestígios visuais" (visual remains) em lugar de "arte", e de "abordagem interpretativa" (interpretative approach) em lugar de "passo exegético" apresentam um novo vocabulário crítico, esses resultantes tanto das chamadas "viradas filosóficas", especificamente a chamada "virada visual [ou icônica]" e a "virada material" nas Ciências Humanas, quanto em refinamentos e novas nuances teórico-metodológicas (p.ex., KEEL, 1992a; UEHLINGER, 2001; SCHROER, 2008b; HULSTER, 2009a; BONFIGLIO, 2016).

\section{Panorama histórico}

A utilização de imagens na interpretação bíblica remonta à Antiguidade. Flávio Josefo, p.ex., em sua caracterização da Bíblia enquanto livro histórico, procurou ilustrar tal história com imagens aos moldes da tradição grega (KEEL, 1992b, p. 359). No Renascimento, assim como textos latinos e gregos eram empregados para auxiliar a interpretação bíblica, imagens também eram como, p.ex., o Arco de Tito e moedas judaicas (IPIAO I, p. 13). Entre os séculos 19 e 20, na esteira de mudanças intelectuais que aceitaram imagens como evidências históricas (BURKE, 2001, p. 10-13), começaram a surgir enciclopédias visuais (SCHROER, 1995, p. 220-223; IPIAO I, p. 1316). Assim, no campo dos Estudos Bíblicos, ao lado das coleções de textos antigo-orientais para uso comparativo com a $\mathrm{BH} / \mathrm{AT}$, como o AOT de Hugo Gressmann (1926 [1909]) e o ANET de James B. Pritchard (1969b [1950]), foram publicadas coleções visuais para uso comparado à $\mathrm{BH} / \mathrm{AT}, \mathrm{o} A O B$ de Gressmann (1926) e ANEP de Pritchard (1969a [1954]). Estes, contudo, ainda apresentavam e utilizavam imagens como ilustrações.

Principalmente influenciado por Hermann Gunkel e Hugo Gressmann, da chamada "Escola da História das Religiões" (Religionsgeschichtlichen Schule), ${ }^{10}$ Othmar Keel, exegeta católico e professor (hoje emérito) da cátedra de Exegese do Antigo Testamento da Universidade de Friburgo, Suíça, publica, em 1972, o seminal Die Welt der altorientalischen Bildsymbolik und das Alte Testament (O mundo da arte simbólica antigo-oriental e o Antigo Testamento; BS). Inspirado pelos historiadores da arte Heinrich Schäfer e Henri Frankfort, que construíram "gramáticas" da arte pré-helenística, isolando aspectos formais e sintáticos, Keel analisa padrões imagéticos no livro de Salmos propondo

10 Estes propuseram um novo escopo comparativo na Exegese Bíblica, que associava a produção cultural humana com textos considerados sagrados. Isso foi possível pelo contexto protestante e favorecido pela teologia liberal desse grupo e, em especial, pela doutrina da "graça comum" (revelation generalis) (KEEL, 1992b, p. 371). Mais recentemente, veja a visão panorâmica apresentada por Keel e Schroer (2005, p. 13-16; 2015, p. 4-6). 
correlações com imagens do AOP. As comparações, contudo, eram feitas através da fenomenologia de Mircea Eliade. Em busca de alcançar maior precisão histórica, Keel passa um período sabático em Jerusalém em 1975 , quando, em contato com Rafael Giveon, se dá conta da existência de milhares de imagens no antigo Israel/Palestina, especialmente em formato de selos de estampar e escaravelhos (KEEL, 1977a, p. 13). Isso the permite analisar sistematicamente textos bíblicos em comparação com imagens locais, no que considero a primeira e mais influente versão de EI. ${ }^{11} \mathrm{Na}$ sequência, Keel passa: (1) da comparação fenomenológica ampla (KEEL, 1996); para (2) a correlação entre motivos iconográficos e porções textuais, especialmente lexemas (KEEL, 1974a; 1974b; 1977a); para, finalmente, (3) a análise paralela e crítica de textos e imagens (KEEL, 1978b; 1980). Com seus estudos sobre Cântico dos Cânticos (KEEL, 1984; 1986b), e na expectativa de criar a série "Comentários Iconográficos do Antigo Testamento" (Bildkommentar zum Alten Testament), ele finalmente desenvolve seu método de "círculos concêntricos".

Com o fracasso da série de comentários, principalmente pela falta de aptidão de exegetas à tarefa (UEHLINGER, 2000, p. 402), Keel migra para a História da Religião do Antigo Israel. Em 1981, assombrado pela dificuldade de acesso ao material, e ciente de que "uma apresentação compreensiva da iconografia canaanita-israelita [...] pressupõe um tratamento sistemático de obras de arte menores, especialmente selos" (KEEL, 1992b, p. 372, tradução minha), Keel inicia um projeto de pesquisa para catalogação e interpretação de selos com vistas à escrita de uma história religiosa da Palestina através de imagens (KEEL, 1986a). Isso resulta na série de catálogos de selos de estampar do antigo Israel/Palestina (CSAP Einl., I-V; CSAJ) e na série de estudos sobre esses selos (SSPI I-IV; cf. SASS; UEHLINGER, 1993). O financiamento para tais projetos pela Swiss National Science Foundation, entre 1981 até 2013, ${ }^{12}$ deu ocasião à criação de um círculo de pesquisa até hoje não rivalizado, o movimento que ficou conhecido como "Escola de Friburgo" ou, como prefiro, "Círculo de Friburgo". ${ }^{13}$ Composto por, entre outros,

11 Em apenas uma década, Keel cobre os principais gêneros textuais encontrados na BH/AT: narrativas (1974a), provérbios (1974a), visões (1978b) e códigos legais (1980a). Ao final desse período, ele retorna à poesia com seus influentes e clássicos estudos no livro do Cântico dos Cânticos (1984; 1986b).

12 Após mais de trinta anos, e já na condição de emérito, Keel tem a renovação de projeto negada. Contudo, em 2020, um novo projeto, agora fundado sob os princípios das Digital Humanities, começou para a continuação da catalogação e migração digital de selos, o Stamp Seals from the Southern Levant, dirigido por Christoph Uehlinger (Zurique), Silvia Schroer (Berna), Stefan Münger (Berna) e Ido Koch (Tel Aviv). Além dos esforços de catalogação, o projeto, integrado por pesquisadores de diversos países e backgrounds disciplinares, também apresenta eixos de pesquisa que mostram o potencial de uso nos selos em diversas disciplinas, como, p.ex., Arqueologia Sul-Levantina, Estudos Bíblicos, História e Egiptologia.

13 Evito aqui a designação "Escola de Friburgo" que, apesar de popular, tem origem desconhecida e não representa de forma acurada o grupo. Hulster (2008, p. 21-25) defende que a mais antiga menção 
Urs Winter, Silvia Schroer, Christoph Uehlinger e Thomas Staubli, o grupo pesquisou sistemas simbólicos do antigo Israel/Palestina sem sucumbir a associações simples entre nomes e perfis iconográficos de deidades (p.ex., ybwh e asherah), tratando imagens como fontes que merecem ser observadas dentre seu próprio contexto de produção e particularidades de produção de sentido (UEHLINGER, 2001; 2007). Nos anos seguintes, o grupo comprovou que "havia imagens em Israel" (SCHROER, 1987) e passou a construir histórias da religião da antiga Palestina/Israel com fontes primárias (i.e., imagens; GGG; IPIAO I-IV; cf. KEEL, 1998). O impacto do grupo sobre a história da religião e exegese é amplamente reconhecido (cf., p.ex., TOORN, 1997; DEVER, 2005; LEWIS, 2020, p. 37-38).

Através de associações com Keel, seus colegas e esforços independentes, a perspectiva se expande nos anos 2000, especialmente após a publicação em língua inglesa de Gods, Goddesses and Images of God (GGG), em 1998. Isso permite que, além dos grupos de fala alemã, que já atuavam no campo (p.ex., FREVEL, 1995; BERLEJUNG, 1998), e associados pontuais (p.ex., CORNELIUS 1994; 2008), uma discussão internacional se forme. Em 2007, GTs sobre "Iconografia e BH/AT" passam a ser sediados tanto na SBL (Society of Biblical Literature), quanto na EABS (European Association of Biblical Studies) (p.ex., HULSTER; SCHMITT, 2009; HULSTER; LEMON, 2014). Isso, junto às publicações nas coleções OBO e OBO.SA, aos compêndios de imagem (CSAP; CSAJ; IPIAO) e ao material instrucional (p.ex., HARTENSTEIN, 2005; IEHBOT; BERLEJUNG, 2019), demonstram o estado atual da EI, que se expande além do círculo originário (p.ex., DOAK, 2019, p. 97-98; PROKOP, 2020, p. 4-5).

\section{Pressupostos e conceitos frequentemente utilizados}

Um pressuposto requerido em toda incursão iconográfica à Bíblia é o de que artefatos visuais antigos e textos bíblicos sejam comparáveis. Com isso, não me refiro apenas ao aspecto - também central - de que textos e imagens são

\footnotetext{
ao termo "Escola de Friburgo" é de William G. Dever (1995, p. 48-49), enquanto Christian Frevel (1995, p. 773, n. 160) a atribui a Silvia Schroer (1995 [1992!], p. 225-226). O mesmo Frevel (1989, p. 78), no entanto, usou a alcunha "Keel-Schule" (al. Escola de [Othmar] Keel) três anos antes de Schroer e o próprio Othmar Keel (1998b, p. 16) parece a atribuir a Frevel e não à sua aluna e colaboradora próxima, Schroer. O termo, contudo, é enganoso, haja vista não haver uma linhagem ou doutrina homogênea, mas um coletivo de pesquisadores de múltiplos campos do saber unidos ao redor de selos de estampar que, na vertente de Estudos Bíblicos, os utilizava para interpretação bíblica. Eu prefiro utilizar o termo "Círculo de Friburgo" por representarem nessa fase "um crescimento desorganizado e espontâneo de interesse em um novo desenvolvimento, como resultado de uma rede que começa a se solidificar e suas doutrinas a se cristalizarem (BECHER; TROWLER, 2001, p. 93-94).
} 
sistemas sígnicos com características próprias ${ }^{14}$ que, de alguma forma, podem ser reunidos. Deve haver, semelhantemente, quadros histórico-culturais e conceituais que permitam que tais comparações sejam feitas de forma responsável. Há uma vasta gama de possibilidades que podem definir a abordagem, resultando em práticas distintas como, p.ex., diferentes recortes cronológicos e geográficos, comparações baseadas em aspectos temáticos, estilísticos, pragmáticos, retóricos, cadeias produtivas etc. Sendo um texto introdutório, apenas apresento aqui as inspirações teórico-filosóficas e artístico-históricas que considero mais frequentes ou que foram seminais nas obras desse contexto intelectual. ${ }^{15}$

\section{Inspirações teórico-filosóficas}

Praticantes de EI geralmente comparam textos e imagens pensando-os enquanto sintomas culturais. Ainda que geralmente só apareça implicitamente (mas cf. LIPPKE, 2011, p. 211), uma pedra angular por trás desses esforços é a chamada "filosofia das formas simbólicas" de Ernst Cassirer. O filósofo da chamada "Escola de Hamburgo", movimento que também teve como personagens Aby Warburg e Erwin Panofsky (cf. LEVINE, 2013), pensava o "sistema das atividades humanas" como a conjunção entre "a linguagem, o mito, a religião, a arte, a ciência, a história” (1972, p. 118). Tal visão sistêmica e, consequentemente, multi-midiática de cultura influenciou indiretamente a EI. De forma particular, ela forneceu inspiração e fundamentação teórico-metodológica para três conceitos influentes na perspectiva.

O primeiro está presente na famosa metodologia qualitativa de análise de conteúdo visual, a iconologia, que nasceu com Aby Warburg, mas se popularizou na variante de Erwin Panofsky. ${ }^{16} \mathrm{O}$ objetivo último e terceiro nível da iconologia de Erwin Panofsky (2014, p. 52-53), consistia na descoberta de

14 Os sistemas de simbolização pictórica e linguístico operam de forma distinta. Para Tonio Höschler (2018, p. 207, tradução minha), “as principais competências de imagens são: primeiro, contar histórias consecutivas; segundo, explicação plausível, abrigando causas e consequências de ações e eventos; e, terceiro, expressão de juízos e avaliações de pessoas e eventos". Imagens, por sua vez, "são muito superiores à linguagem na representação de seus temas com um alto grau de impacto sensorial imediato. Tal potencial de 'presentificar' tem sido recentemente objeto de investigação acadêmica”. Eggler et al. (2006) ressalta a facilidade de imagens representarem com maior facilidade relações complexas (p.ex., proporções, conexões, conceitos etc.), enquanto textos sequências de ações e descrições tópicas. É também ressaltado que termos não são tão facilmente reconhecidos fora do alcance linguístico de dada língua. A partir disso, Hölscher (2018, p. 207, tradução minha) demonstra que enquanto estudos anteriores enfatizaram tais estruturas paralelas (i.e., textos $v$ s imagens), "hoje o interesse se deslocou para as diferentes capacidades cooperativas das duas mídias" (i.e., textos $e$ imagens).

15 Evito, contudo, a repetição dos autores e autoras mencionados no panorama histórico.

16 Não é necessário expor o famoso esquema de Panofsky, este que, apesar de muito criticado, continua um "clássico" na análise historicamente orientada de imagens (cf. UEHLINGER, 2015, p. 394-399). 
"sintomas culturais", seguindo Cassirer ${ }^{17}$ e o sociólogo do conhecimento Karl Mannheim. ${ }^{18}$ Para o historiador da arte, sem esse objetivo, "o famoso afresco de Leonardo da Vinci" seria apenas a "Última Ceia", cujas características formais são facilmente e frequentemente descritas pela História da Arte convencional. No entanto, "quando tentamos compreendê-la como um documento da personalidade de Leonardo, ou da civilização da Alta Renascença italiana, ou de uma atitude religiosa particular", a obra passa a ser evidência desse "algo mais". Na linha da história cultural burckhardtiana, o aspecto é fundamental tanto na integração de múltiplas fontes, quanto na distinção dos três diferentes níveis de interpretação.

A supracitada interação entre diferentes produções/expressões culturais ${ }^{19}$ também forneceu importante fundamento para o conceito de sistema simbólico cultural do antropólogo Clifford Geertz (2015, p. 21) que, na introdução à sua influente coletânea $A$ Interpretação das Culturas, disse que os textos ali contidos eram consequência do aumento de interesse na antropologia e estudos sociais "no papel das formas simbólicas na vida humana", emprestando a terminologia de Cassirer. A ideia de sistema simbólico ${ }^{20}$ é central na perspectiva e, de forma especial, em trabalhos voltados à História da Religião do Antigo Israel (p.ex., GGG; IPIAO), que representam a fase de catalogação e sínteses histórico-religiosas da Palestina por imagens. Muitos, nesse aspecto, consideram como objetivo final da história da religião da antiga Palestina/ Israel a "descrição densa" e identificação dos múltiplos "sistemas simbólicos".

O terceiro e último conceito que deve ser mencionado aqui é o de constelação. O egiptólogo Jan Assmann (1977, p. 11-12, 43) utilizou a ideia

17 É importante ressaltar que havia um ambiente de mútua-influência entre os estudiosos da "Escola de Hamburgo", assim, em certos pontos, a obra de Panofsky deriva-se da filosofia de Cassirer (LEVINE, 2013, p. 163), enquanto Warburg e Panofsky influenciavam o filósofo (MÜLLER, 2011, p. 285).

18 O capítulo de Mannheim (1952, p. 33, tradução minha, grifo original) On the Interpretation of Weltanschaunng é, por muitos autores, considerado outro gatilho para o terceiro nível da iconologia de Panofsky. Lá, ele pergunta: "Qual tipo de tarefa é enfrentada pelo estudante de uma disciplina cultural e histórica (historiador da arte, da religião e, possivelmente, também sociólogo) quando ele procura determinar a perspectiva global de uma época (Weltanschaunng), ou traçar manifestações parciais ao redor dessa entidade que compreende tudo? A entidade designada pelo conceito Weltanschaunng nos é dada? Se assim for, como ela é dada? Como se compara o seu caráter de dados com o de outros dados nas disciplinas culturais e históricas?”.

19 Ou, para ser semioticamente preciso, "textos", estes que podem ser literários, pictóricos, gestuais, sonoros etc.

20 Que também foi influenciada pelo estrutural-funcionalismo de Talcott Parsons (1991) e pelo conceito de tradição de Edward Shils (1981). Para Parsons, cada função do sistema de ação social tinha sistema de ação correspondente: para a adaptação, havia o organismo de comportamento; para a realização das metas, o sistema da personalidade; para a integração, o sistema social; e, por fim, para a manutenção dos modelos, o sistema social. Shils (1981, p. 12-13), por sua vez, utiliza a ideia de "constelações de símbolos", que seriam passados através da tradição, que, para ele, seria tudo que é passado adiante, incluindo "objetos materiais, crenças sobre todos os tipos de coisas, imagens de pessoas e eventos, práticas e instituições", assim como "inclui edifícios, monumentos, paisagens, esculturas, pinturas, livros, ferramentas, máquinas". 
de formas simbólicas, entre outras, para tratar os múltiplos papéis de divindades egípcias e, consequentemente, as diferentes formas como mitos, ritos e textos se relacionavam. Para Assmann (1995, cap. 2, tradução minha), o discurso mitológico é construído por diferentes "ícones", uma "expressão ou articulação de conteúdos que podem ser realizados tanto na linguagem quanto na imagem". Ele chamou a totalidade de pontos de referência que podem se transformar em mito de "constelação", que seria aquilo que mantém a coerência dos mitos no decorrer do tempo (1982, p. 38). Segundo a interpretação do Círculo de Friburgo, tais constelações são acessadas via motivos iconográficos, o que gerou uma ênfase particular na interpretação de imagens do grupo. Nisso, no contexto suíço, o conceito de constelação não é apenas fundacional metodologicamente, como bem argumentaram Weissenrieder e Wendt (2005, p. 20-27), mas também foi utilizado como estrutura argumentativa em muitas obras dessa linhagem (p.ex., SCB; MBB).

\section{Inspirações artístico-históricas}

Além da inspiração filosófica acima, há duas características formais da arte antigo-oriental e egípcia que forneceram base para comparações entre textos bíblicos e imagens antigas. Tais aspectos, embora desenvolvidos a partir da História da Arte, não estão apenas restritos à estilística artística, mas refletem formas de pensar do AOP.

O primeiro é, também, um dos aspectos mais evidentes da arte egípcia, sua perceptualidade ou perspectiva. Heinrich Schäfer (2002, p. 91-92), em seu estudo sobre a arte egípcia, chamou a forma peculiar dos egípcios antigos representarem todos os elementos imagéticos frontalmente de geradvorstellig, algo como "apresentação frontal". Sua aluna, Emma Brunner-Traut, chamou tal característica de aspectiva, para contrapor à prática posterior grega, essa chamada perspectiva. Segundo Brunner-Traut (2002, p. 422, 430, tradução minha, grifo original), ao contrário da arte helenística ou grega posterior, "um egípcio retrata aquilo que está representando parte por parte como realmente e idealmente $\hat{e}$. Como resultado, um quadrado é sempre um quadrado, não importando o ângulo de visão da obra, assim como um pé, um braço etc. O chamado aspectivismo, assim, denota uma forma de organização mental, ele "é a forma exclusiva de ver o oposto na presença do objeto, não para frente ou para trás no tempo, e não se movendo para fora de seus limites". Tal programa, apesar de oriundo do Egito Antigo, integrou práticas de representação artística em todo o contexto do AOP.

O segundo aspecto foi proposto por Henri Frankfort (1961, p. 4, tradução minha, grifo original), que disse que "o pensamento antigo - mitopoético, pensamento 'criador de mitos' - admitia, lado a lado, um número limitado de 
percepções, que eram consideradas válidas simultaneamente, cada qual em seu contexto próprio, correspondendo a uma via de abordagem definida". Assim, a representação não era exclusivista, mas era tão aditiva quanto paratática (HARTENSTEIN, 2005, p. 178), algo que o orientalista chamou multiplicidade de abordagens (multiplicity of approaches). Tal agrupamento aditivo e cumulativo de características, embora mais evidente em imagens, também ocorre em práticas retórico-textuais como, p.ex., no conhecido fenômeno da poética hebraica chamado "paralelismo dos membros" (parallelismus membrorum). Esse aspecto também pode ser visto na escrita por hieróglifos, estes que, embora se derivem da representação de objetos concretos, mantêm uma dimensão simbólica adicional, ambas podendo ser lidas simultaneamente e de forma não-excludente.

\section{Vertentes metodológicas}

Acredito que tenha ficado evidente acima que EI não é um método, mas uma perspectiva. Isso implica não apenas a falta de padronização, ${ }^{21}$ mas também as múltiplas abordagens empíricas utilizadas por pesquisadoras e pesquisadores. Conquanto os últimos anos tenham visto diversas tentativas de estabelecer bases teórico-metodológicas e alcançar padronização, esse é um estágio ainda não alcançado. Ambos os movimentos, de busca por padronização e diversificação, são vistos nos estudos de caso do IEBHOT. Aqui, enfatizo apenas duas vertentes metodológicas nos últimos cinquenta anos que considero centrais, essas que Hulster (2008, p. 21-258) chamou, respectivamente, de abordagem indutiva e dedutiva. ${ }^{22}$ Em contraposição, eu prefiro caracterizá-las pela sua respectiva ênfase sintética e integrativa.

\section{Exegese iconográfica como sintese de pesquisas em textos e imagens}

A primeira abordagem faz análise crítica de textos $e$ imagens de forma independente, para, depois, aferir possíveis pontos de convergência e diver-

\footnotetext{
${ }^{21}$ A falta de padronização se deve à ausência de um aparato teórico-metodológico claro e coerente durante a fundação da perspectiva. Keel sempre preferiu agir indutivamente, em forma de estudos de caso. Um exemplo, é a tréplica de Keel a Helga Weippert, após ela ter criticado o método de Jahwe-Visionen und Siegelkunst. Keel (1978a, p. 40) responde: "princípios exegéticos só podem ser formulados de forma indutiva” (1978a, p. 40). Só após vinte anos interpretando a BH/AT com imagens ele expõe sua metodologia e, ainda assim, só a aborda em um apêndice de sete páginas após três longos estudos de caso (1992a, p. 267-273).

22 Contudo, ele ressalta que, mesmo nas abordagens indutivas, há metodologias e raciocínio dedutivo integrado. Hulster (2008, p. 6, n. 26, tradução minha) afirma que "uma abordagem dedutiva tem seu ponto de partida no método, enquanto a abordagem indutiva na prática". No glossário, Hulster (2008, p. 466, tradução minha) define dedutivo como "(raciocínio) do geral ao particular" e indutivo como “(raciocínio) do particular ao geral”.
} 
gência. Tal prática, chamada "holística", 23 é evidente no Círculo de Friburgo (p.ex., GGG; IPIAO; UEHLINGER, 2001; 2007). No contexto, os esforços respectivos de catalogação e análise de iconografia da antiga Palestina/Israel aliado aos compromissos docentes de exegese bíblica nos departamentos bíblicos geravam insights que eram aproveitados bilateralmente. Por isso, não há um procedimento metodológico fixo, pois, à semelhança do modelo de Panofsky, "a intuição do respectivo pesquisador é parte do método", pois "ela ou ele usa sua fascinação particular e interesse em um certo tipo de motivo para ter uma impressão geral de motivos similares [...] geralmente transgredindo diferente tipos de mídia" (MÜLLER, 2011, p. 286, tradução minha). O que existe, em contraposição, é a ênfase em motivos iconográficos e constelações simbólicas.

Há, contudo, dois procedimentos metodológicos que merecem menção. Primeiro, a forma de Keel interpretar imagens. ${ }^{24}$ Partindo de Panofsky (2014, p. 64-65), Keel ${ }^{25}$ criou um método considerando as críticas ao método panofskyano e os insights do historiador da arte suíço, Oskar Bätschmann. Isso, aliado ao objeto de estudos e enfoque prioritário - i.e., "a arte antigo-oriental como parte das culturas do oriente antigo e, especialmente, suas religiões" (KEEL, 1992a, p. 271) -, gerou um método distinto (cf. Tabela 1). Como principais diferenças do método panofskyano estão: (1) a não-progressividade dos passos, que podem ser tomados de forma independente, a depender da questão e interesse de pesquisa; (2) o enfoque em motivos, o que vem não apenas da ligação à ideia de constelação, mas também pelas práticas de miniaturização, algo muito presente em uma terra fronteiriça como era Canaã, dentre o contexto do AOP (KEEL, 1990; IPIAO I, p. 23-25); (3) o "direito das imagens de serem vistas" (Das Recht der Bilder gesehen zu werden), i.e., não recorrer apressadamente a textos para interpretar imagens, como faz Panofsky; (4) a ênfase na qualidade, manufatura e localização arqueológica de artefatos visuais, algo advindo da ênfase arqueológica. ${ }^{26}$ Nisso, a força do

23 Keel a chamou assim pelo fato de que ela "não se refere a um texto específico, livro ou mesmo a toda a Bíblia, mas a toda uma cultura em um determinado momento" (1998a, p. 219, tradução minha).

24 Não é possível dizer que tal abordagem seja do "Círculo de Friburgo", haja vista cada estudioso ter construído sua própria variante metodológica. Isso é particularmente notável no caso de Schroer e Uehlinger que, apesar de terem iniciado seus estudos com Keel, formaram ao redor de si suas próprias vertentes interpretativas.

25 Uehlinger também teve participação nesse esquema (cf. KEEL, 1992a, p. 267, n. 1). Uehlinger também compilou um método para fins didáticos e focado na história das religiões. Este, contudo, jamais foi publicado.

${ }^{26}$ Esse aspecto, em particular, não parece ter sido plenamente compreendido por Weissenrieder e Wendt (2005, p. 26, tradução minha), que dizem que "só é possível usar [a qualidade técnica ou know-how do artesão] como método de controle quando se considera uma alta continuidade de estilo com procedimentos técnicos padrões". Não por coincidência, é justamente essa continuidade que fundamenta a análise de Keel. Por ex., foi só apenas ao analisar 7.500 selos de estampar que Keel (1990, p. 202, tradução minha) diz, utilizando o caso dos selos que ilustram o deus egípcio Ptah, que "a arte em 
método está em sua ênfase diacrônica e temática, que pode ser facilmente integrada à exegese histórico-crítica, especialmente na sessão da "história da tradição" ou "história dos motivos".

Tabela 1. Esquema interpretativo de Keel [e Uehlinger] (1992a, p. 273)

\begin{tabular}{|c|c|c|c|}
\hline $\begin{array}{l}\text { Objeto da } \\
\text { interpretação }\end{array}$ & Questão principal & Passos metodológicos & \begin{tabular}{|l} 
Controle \\
e avaliação
\end{tabular} \\
\hline $\begin{array}{l}\text { Motivo } \\
\text { (elemento da } \\
\text { imagem, ico- } \\
\text { nema) }\end{array}$ & $\begin{array}{l}\text { Qual fenômeno está } \\
\text { sendo representado } \\
\text { pelo motivo? Rela- } \\
\text { ção entre significante } \\
\text { e referente. }\end{array}$ & $\begin{array}{l}\text { Crítica/história dos motivos (tra- } \\
\text { ços biológicos-transculturais, traços } \\
\text { culturais). } \\
\text { Convenção de representação (pic- } \\
\text { tórica, linear; realista, esquemático- } \\
\text {-artística). }\end{array}$ & $\begin{array}{l}\text { Qualidade técnica } \\
\text { (pergunta sobre o } \\
\text { estado de conser- } \\
\text { vação da imagem, } \\
\text { habilidade do fabri- } \\
\text { cante, técnica). }\end{array}$ \\
\hline $\begin{array}{l}\text { Cena/Tema } \\
\text { (tipo de } \\
\text { imagem, tema, } \\
\text { ícone) }\end{array}$ & $\begin{array}{l}\text { Como os motivos } \\
\text { estão conectados às } \\
\text { declarações ligadas } \\
\text { ao conteúdo? Re- } \\
\text { lação entre signifi- } \\
\text { cado e significante } \\
\text { (referente). }\end{array}$ & $\begin{array}{l}\text { Críticas/história dos temas (mo- } \\
\text { tivos culturalmente ou transcultu- } \\
\text { ralmente verificáveis estereotipica- } \\
\text { mente combinados com base em } \\
\text { condições biológicas ou sociais), } \\
\text { paralelos sincrônicos e diacrônicos } \\
\text { e variantes de tais combinações. } \\
\text { Composição (proporções, re- } \\
\text { lações, formas e cores, organi- } \\
\text { zação associativa, aspectiva ou } \\
\text { perspectiva da imagem). } \\
\text { Co-texto (com quais outras } \\
\text { cenas essa cena está geralmente } \\
\text { combinada?). }\end{array}$ & $\begin{array}{l}\text { Qualidade de } \\
\text { imagem } \\
\text { (original ou cópia, } \\
\text { uniformidade do } \\
\text { trabalho, acréscimos } \\
\text { posteriores, mãos } \\
\text { diferentes). }\end{array}$ \\
\hline $\begin{array}{l}\text { Decorações } \\
\text { (icontexto [i.e., } \\
\text { que de acordo } \\
\text { com a história } \\
\text { dos motivos, } \\
\text { estaria além do } \\
\text { significado da } \\
\text { imagem]) }\end{array}$ & $\begin{array}{l}\begin{array}{l}\text { Onde são colocadas } \\
\text { decorações (moti- } \\
\text { vos, cenas) e com } \\
\text { qual finalidade? }\end{array} \\
\text { Significado em } \\
\text { termos de qualidade } \\
\text { decorativa. } \\
\text { Função e significado } \\
\text { de uma imagem no } \\
\text { contexto da história } \\
\text { das ideias. }\end{array}$ & $\begin{array}{l}\text { Crítica/história da decoração (com } \\
\text { quais decorações o objeto porta- } \\
\text { dor da imagem está combinado, } \\
\text { como paredes de igrejas, quartos, } \\
\text { lápides ou selos decorados). } \\
\text { Construção da decoração de } \\
\text { forma geral. } \\
\text { Sitz im Leben da imagem e/ou do } \\
\text { portador da imagem. }\end{array}$ & $\begin{array}{l}\text { Qualidade da } \\
\text { decoração } \\
\text { (questão sobre } \\
\text { a adequação de } \\
\text { uma determinada } \\
\text { decoração para um } \\
\text { determinado local). }\end{array}$ \\
\hline
\end{tabular}

miniatura [i.e., selos de estampar] é primariamente um indicador da religião popular, principalmente ali, onde suas obras foram criadas a partir de materiais baratos". 
Enquanto o método acima apenas pensava a análise de imagens, a integração entre textos e imagens era feita pelo que Keel chamou de "círculos concêntricos", que auxilia na visualização das diferentes esferas nas quais textos e imagens interagem, além de notar quais aspectos da cultura haviam sido utilizados pelos textos. Na prática, a exegeta ou o exegeta divide a interpretação em níveis ou "círculos" interpretativos. Cada um deles representa uma interface distinta de comparação, que parte do texto e se expande até a cultura, de forma geral: (1) o contexto literário imediato (i.e., perícopes anteriores e posteriores); (2) o contexto literário do livro bíblico; (3) a $\mathrm{BH} /$ AT de forma geral; (4) a terra na qual o texto supostamente teria sido escrito. Neste último círculo, imagens entram em jogo, pois "o mundo natural tem inúmeros aspectos, mas a cultura está interessada em apenas alguns deles", levando à prioridade de aspectos culturais sobre naturais e resultando na necessidade de "estudar imagens figurativas em selos, amuletos, marfins e outros valores pelos quais as pessoas abastadas que escreveram Cantares estavam diariamente rodeadas" (KEEL, 1994c, p. 27, tradução minha).

Esse tipo de interpretação histórico-culturalmente informada da Bíblia foi defendida nos "nove princípios interpretativos" de Keel (1984) ${ }^{27}$ para Cantares. Esses visavam aplacar a interpretação naturalista de textos bíblicos e arte local da antiga Palestina/Israel. Enquanto, no princípio, essa atitude foi fundamentada nos estudos de Gunkel e a "psicologia profunda" de C. G. Jung, ${ }^{28}$ a partir de 1984, Keel encontra em Ernst Gombrich um novo aporte, com sua famosa frase "a arte nasce da arte, não da natureza" (GOMBRICH apud KEEL, 1984, p. 23, tradução minha). ${ }^{29}$ Assim, ele defende que "canções e poemas são sempre arte" e "apesar da natureza desencadear sentimentos, quando se chega à expressão concreta, o poema ou a pintura, o artista é primeiramente guiado por modelos artísticos, os quais no melhor caso ele modifica (da natureza) de acordo com a lei do "padrão e correção"” (KEEL, 1984, p. 23, tradução minha).

27 Respectivamente: (1) os poemas em Cantares são canções de amor; (2) as canções revelam aspiração/ saudade (Sehnsucht); (3) tal aspiração/saudade é construída através de estereótipos; (4) o horizonte primário de entendimento é a Palestina e o Antigo Testamento; (5) a arte da Mesopotâmia e Egito só deve ser utilizada na falta de arte local; (6) o mundo retratado (tanto natural quanto simbólico) é a Palestina com seus símbolos eróticos; (7) o repertório de imagens da Palestina cria o topos de interpretação; (8) o teomorfismo pode fazer referência a esse mundo; (9) a antropologia bíblica é dinâmica, não atada a qualquer forma/conceito particular.

28 Isso é visto desde a tese de doutorado de Keel (1969, p. 34, 55-56), quando ele se opõe à historicização dos “inimigos" no livro de Salmos e, também, em Jabwes Entgegnung an Ijob (1978b, p. 5, 11-12), quando ele critica exegetas por buscarem em manuais de ciências naturais clarificação sobre Jó 38-41.

29 Essa é uma frase constantemente repetida por Keel (p.ex., 1985b, p. 27; 1992b, p. 25; 1994c, p. 27). 
$\mathrm{Na}$ tentativa de criar um método que integrasse artefatos visuais à exegese histórico-crítica convencional, Izaak de Hulster criou o que parece ser, até o momento, o único método explícito de EI. Para Hulster (2011; cf. 2008; 2009a), há duas possibilidades de integração de imagens à exegese: (1) no estágio da história da tradição (Traditionsgeschichte $e^{30}$ ); ou (2) no estágio de seleção do contexto histórico (Historische Ort). A escolha entre um e outro estaria ligada à possibilidade de as imagens escolhidas clarificarem, respectivamente, o contexto histórico-intelectual (geistesgeschichtlichen) ou o contexto histórico-cultural do texto. Um aspecto central e que distingue o trabalho de Hulster (2009a, p. 29-30) nessa etapa é o início com o texto. Ele se preocupava, afinal, em formalizar EI como método dentre o arsenal da exegese textual da $\mathrm{BH} /$ AT. ${ }^{31}$ Sua mais importante contribuição foi a discussão atualizada sobre o papel de textos e imagens dentre o processo de interpretação (cf. mais recentemente, BONFIGLIO, 2016). Ele sumariza seu procedimento exegético em sete passos (cf. Tabela 2).

Tabela 2. Passos metodológicos de Hulster (2009a, p. 103, cf. p. 261)

\begin{tabular}{|c|c|c|}
\hline 1 & Ponto de partida & Interação com o texto que estimula a exegese. \\
\hline 2 & Delimitação textual & \\
\hline 3 & $\begin{array}{l}\text { Datação e } \\
\text { contextualização }\end{array}$ & Dentre uma comunidade comunicativa ou cultura. \\
\hline 4 & Procura por imagens & Filtradas por tema e cultura. \\
\hline 5 & Análise de imagens & $\begin{array}{l}\text { Utilizando os três níveis de interpretação (Panofsky) e } \\
\text { consideração do maior número possível de literatura relevante } \\
\text { sob múltiplas abordagens (Bätschmann). }\end{array}$ \\
\hline$\overline{6}$ & Aplicação & $\begin{array}{l}\text { Comparação (examinando similaridades e contrastes) e } \\
\text { combinando as conclusões da interpretação de texto e imagem. }\end{array}$ \\
\hline$\overline{7}$ & Sumário crítico & $\begin{array}{l}\text { Clarificação do texto e fundamentação, complementação e } \\
\text { correção de suas interpretações prévias. }\end{array}$ \\
\hline
\end{tabular}

30 Apesar do texto alemão de Berlejung (2019, p. 44) não trazer essa possibilidade, a tradução norte-americana do mesmo diz que na crítica da tradição, "tópicos individuais, ideias e motivos que estão contidos em um texto bíblico, mas mostram evidência de transmissão independente seja em outros textos bíblicos ou no contexto mais amplo do contexto do antigo Oriente Próximo são isolados e investigados, p.ex., através da análise de campos semânticos ou comparação com textos extra-bíblicos e iconografia" (BERLEJUNG, 2012, p. 38-39, tradução minha, grifo meu). Possivelmente, a omissão alemã se deva ao fato da prática ser pressuposta.

31 Hulster (2009b) menciona duas outras entradas possíveis: (1) imagem, (p.ex., IPIAO); (2) tema (p.ex., STRAWN, 2005). Essas, contudo, não integram seu método. 


\section{Conclusão}

Certa vez, Keel (1985b, p. 38, tradução minha) disse que "há grupos e círculos de acadêmicos que aprenderam a ler, mas nunca a ver. Não se pode culpá-los por isso, contudo, eles devem reconhecer os próprios limites de sua competência". Procurei demonstrar acima que acessar o chamado "mundo bíblico" não implica apenas resolver enigmas linguísticos. Mais do que isso, interpretar a Bíblia também envolve aprender a enxergar o mundo, de forma literal e figurada, como os povos que escreveram ou foram retratados na Bíblia. Nisso, enquanto a habilidade de interpretar imagens não pareça ser requerida ou desejável a priori a uma área de estudos que recebe o nome de um artefato textual como Estudos Bíblicos, os resultados da EI nos últimos cinquenta anos mostram de forma inconteste sua importância.

De um ponto de vista historiográfico, o esforço é justificado pela óbvia necessidade do pesquisador ou pesquisadora acessar o maior número possível de documentos do passado para sua reconstrução histórica (UEHLINGER, 2015 , p. 393). Isso se torna particularmente relevante no contexto sul-levantino, onde fontes visuais são mais abundantes do que fontes textuais. Enquanto poucos textos do chamado antigo Israel foram encontrados no registro arqueológico, já foram, por exemplo, escavados mais de 10 mil itens visuais da chamada "arte em miniatura", no formato de selos de estampar. Isso torna a análise histórico-cultural sem imagens e exclusivamente dependente de textos tardios omissa ou desinformada. Além disso, como Schroer (1995, p. 220) argumentou, os próprios textos bíblicos pressupõem a cultura visual de seu tempo, descrevendo-lhes obras artísticas (p.ex., Ez 23.14s), mencionando-as implicitamente em suas descrições (p.ex., Is 6; Ez 1; Zc 4), ou tratando temas similares.

O estudioso e a estudiosa da Bíblia, afinal, de muitas maneiras, se assemelham a críticos da cultura. Eles não podem, dessa forma, se dar ao luxo de se confinarem a tradições acadêmicas datadas ou a pautas normativas ocultas, como a escolha de fontes pela mídia ou por um desejo latente de legitimação ideológica e/ou teológica. Refiro-me à hierarquização ou opção por fontes a partir de critérios como pertença ou crença religiosa, ou filiação acadêmico-traditiva. Quando esses aspectos deixam de ditar práticas, é evidente que a EI é um valioso item a ser integrado à caixa de ferramentas metodológicas de exegetas, assim como os novos e atraentes limites que a pesquisa bíblica pode alcançar nos anos vindouros. 


\section{Abreviaturas}

ANEP - Ancient Near East Pictures in Images Relating to the Old Testament (PRITCHARD, 1969a)

ANET - Ancient Near East Texts Relating to the Old Testament (PRITCHARD, 1969b)

AOB - Altorientalische Bilder Zum Alten Testament (GRESSMANN, 1927)

AOP - Antigo Oriente Próximo

AOT - Altorientalische Texte Zum Alten Testament (GRESSMANN, 1926)

BH/AT - Bíblia Hebraica / Antigo Testamento

BS - Die Welt der altorientalischen Bildsymbolik und das Alte Testament (KEEL, 1996)

CSAJ - Corpus der Siegel-Amulette aus Jordanien (EGGLER; KEEL, 2006)

CSAP - Corpus der Stempelsiegel-Amulette aus Palästina/Israel (KEEL, 1995a, 1997a, 2010b, 2010c, 2013, 2017a)

GGG - Gods, Goddesses and Images of God (KEEL; UEHLINGER, 1998).

IEHBOT - Iconographic Exegesis of the Hebrew Bible/Old Testament (HULSTER; STRAWN; BONFIGLIO, 2015)

IPIAO - Die Ikonographie Palästinas/Israels und der Alte Orient (SCHROER; KEEL, 2005; SCHROER, 2008a, 2011, 2018)

MBB - Menschenbilder der Bibel (STAUBLI; SCHROER, 2014).

SCB - Simbolismo do Corpo na Bíblia (SCHROER; STAUBLI, 2003)

SSPI - Studien zu den Stempelsiegeln aus Palästina/Israel (KEEL; SCHROER, 1985; KEEL; KEEL-LEU; SCHROER, 1989; KEEL; SHUVAL; UEHLINGER, 1990; KEEL, 1994b).

\section{Referências bibliográficas}

ASSMANN, Jan. Die Verborgenheit des Mythos in Ägypten. Göttinger Miscellen, v. 25, p. 7-43, 1977.

ASSMANN, Jan. Die Zeugung des sohnes. Bild, spiel, erzählung und das problem des ägyptischen mythos. In: ASSMANN, Jan; BURKERT, Walter; STOLZ, Fritz. Funktionen und leistungen des mythos. Freiburg; Göttingen: Universitätsverlag Freiburg; Vandenhoeck \& Ruprecht, 1982, p. 13-63. (OBO, 48).

ASSMANN, Jan. Egyptian solar religion in the New Kingdom: Re, Amun, and the Crisis of Polytheism. Londres; Nova Iorque: Routledge, 1995.

BECHER, Tony; TROWLER, Paul R. Academic tribes andtTerritories: intellectual enquiry and the culture of disciplines. 2. ed. Buckingham; Philadelphia: SRHE; Open University Press, 2001.

BERLEJUNG, Angelika. Die Theologie der Bilder: herstellung und einweihung von kultbildern in Mesopotamien und die alttestamentlicche bilderpolemik. Freiburg; Göttingen: Universitätsverlag Freiburg; Vandenhoeck \& Ruprecht, 1998. (OBO, 162). 
BERLEJUNG, Angelika. Quellen und methoden. In: GERTZ, Jan C. et al. Grundinformation Altes Testament. 6. ed. Göttingen: Vandenhoeck \& Ruprecht, 2019, p. 21-58. [Sources and methhods. In: GERTZ, Jan C. et al. T\&T Clark Handbook of the Old Testament: an introduction to the literature, religion, and history of the Old Testament. Trad. Thomas Ripplinger. Londres; Nova Iorque: T\&T Clark, 2012, p. 3-57].

BONFIGLIO, Ryan P. Reading images, seeing texts: towards a visual hermeneutics for Biblical Studies. Freiburg; Göttingen: Universitätsverlag Freiburg; Vandenhoeck \& Ruprecht, 2016. (OBO, 280).

BRUNNER-TRAUT, Emma. Epilogue: aspective. In: SCHÄFER, Heinrich. Principles of egyptianaArt. Oxford: Oxford University Press, 2002, p. 421-448.

BURKE, Peter. Eyewitnessing: the uses of images as historical evidence. Londres: Reaktion Books, 2001. (Picturing History).

CASSIRER, Ernst. Antropologia filosófica: ensaio sobre o homem: introdução a uma filosofia da cultura humana. Trad. Vicente Felix de Queiroz. São Paulo: Mestre Jou, 1972.

CORNELIUS, Izak. Iconography, iconology, II. HB / OT. In: ALLISON, D. C. et al. (eds.). Encyclopedia of the Bible and Its reception. Vol. 12. Berlin; Boston: Walter de Gruyter, 2016, p. 783-785.

CORNELIUS, Izak. The iconography of the Canaanite Gods Reshef and Ba'al: Late Bronze and Iron Age I Periods (c. 1500-1000 BCE). Freiburg; Göttingen: Universitätsverlag Freiburg; Vandenhoeck \& Ruprecht, 1994. (OBO, 140).

CORNELIUS, Izak. The many faces of the Goddess: the iconography of the Syro-Palestinian Goddesses Anat, Astarte, Qedeshet, and Asherah c. 1500-1000 BCE. Freiburg; Göttingen: Universitätsverlag Freiburg; Vandenhoeck \& Ruprecht, 2008. (OBO, 204).

CORNELIUS, Izak. The study of the Old Testament and the material imagery of the ancient Near East, with a focus on the body parts of the Deity. In: JONKER, Louis C. (ed.). Congress Volume Stellenbosch, South Africa. Leiden; Boston: Brill, 2017, p. 195-227. (VTSup, vol. 177).

DEVER, William G. "Will the Real Israel, please, Stand up?”. Part II: Archaeology and the religions of ancient Israel. BASOR, v. 298, p. 35-58, 1995.

DOAK, Brian R. Heroic bodies in ancient Israel. Oxford: Oxford University Press, 2019.

EGGLER, Jürg; KEEL, Othmar. Corpus der siegel-amulette aus Jordanien. Vom Neolithikum bis zur Perserzeit. Freiburg; Göttingen: Universitätsverlag Freiburg; Vandenhoeck \& Ruprecht, 2006. (OBO SA, 25).

EGGLER, Jürg; KEEL, Othmar; SCHROER, Silvia; UEHLINGER, Christoph. Ikonographie. In: Das Wissenschaftliche Bibellexikon im internet, 2006. Disponível em: http://www. bibelwissenschaft.de/stichwort/21778/. Acesso em 12/02/2021.

EXUM, J. Cheryl. Art as biblical commentary: visual criticism from Hagar the wife of Abraham to Mary the mother of Jesus. Londres; Nova Iorque: T\&T Clark, 2019.

FITZMYER, Joseph A. The interpretation of the Scripture: in defense of the historical-critical method. New York: Paulist Press, 2008.

FLYNN, Gabriel. Theological renewal in the first half of the Twentieth Century. In: GAILlardeTZ, R. R. (ed.). The Cambridge Companion to Vatican II. Cambridge: Cambridge University Press, 2020, p. 19-40. 
FRANKFORT, Henri. Ancient Egyptian religion: an interpretation. Nova Iorque: Harper \& Row Publishers, 1961.

FREVEL, Christian. Aschera und der Ausschließlichkeitsanspruch YHWHs: Beiträge zu literarischen, religionsgeschichtlichen und ikonographischen aspekten der ascheradiskussion. 2 vols. Weinheim: Beltz Athenaum, 1995. (BBB, 94).

FREVEL, Christian. Dies ist der Ort, von dem geschrieben steht...' Zum Verhältnis von Bibelwissenschaft und Palästinaarchäologie. BN, v. 47, p. 35-89, 1989.

GEMÜNDEN, Petra von. Vegetationsmetaphorik im Neuen Testament und seiner Umwelt. Eine Bildfelduntersuchung. Freiburg; Göttingen: Universitätsverlag Freiburg; Vandenhoeck \& Ruprecht, 1993. (NTOA, v. 18).

GRESSMANN, Hugo. Altorientalische Bilder zum Alten Testament. 2. ed. Berlin: Walter de Gruyter, 1927.

GRESSMANN, Hugo. Altorientalische Texte zum Alten Testament. 2. ed. Berlin: Walter de Gruyter, 1926.

HARTENSTEIN, Friedhelm. Altorientalische ikonographie und exegese des Alten Testaments. In: KREUZER, S.; VIEWEGER, D. (eds.). Proseminar I Altes Testament. ein arbeitsbuch. 2. ed. Stuttgart: Kohlhammer, 2005, p. 173-86.

HÖLSCHER, Tonio. Visual Power in Ancient Greece and Rome: between Art and Social Reality. Oakland: University of California Press, 2018.

HULSTER, Izaak de. Iconographic exegesis and Third Isaiah. Tübingen: Mohr Siebeck, 2009a. (FAT 2, 36).

HULSTER, Izaak de. Illuminating images. A historical position and method for iconographic exegesis. In: HULSTER, Izaak de; SCHMITT, Rüdiger. (eds.). Iconography and biblical studies. Proceedings of the iconography sessions at the Joint EABS/SBL Conference, 22-26 July 2007, Vienna, Austria. Münster: Ugarit-Verlag, 2009b, p. 139-162. (AOAT, 361).

HULSTER, Izaak de. Illuminating images: an iconographic method of Old Testament exegesis with three case studies from Third Isaiah. 2008. 475f. Tese (PhD., Teologia) - University of Utrecht, 2008.

HULSTER, Izaak de. Ikonographische exegese. In: Das Wissenschaftliche Bibellexikon im Internet, 2011. Disponível em: https://www.bibelwissenschaft.de/stichwort/14720/. Acesso em 12/02/2021.

HULSTER, Izaak de. Of angels and iconography: Isaiah 6 and the biblical concept of Seraphs and Cherubs. In: HULSTER, Izaak de; STRAWN, Brent A.; BONFIGLIO, Ryan P. (eds.). [IEHBOT] Iconographic exegesis of the Hebrew Bible/Old Testament. an introduction to its method and practice. Göttingen: Vandenhoeck \& Ruprecht, 2015, p. 147-164.

HULSTER, Izaak de; LEMON, Joel M. (eds.). Image, text,exegesis: iconographic interpretation and the Hebrew Bible. Londres: Bloomsbury, 2014. (LHBOTS, 588).

HULSTER, Izaak de; SCHMITT, Rüdiger. (eds.). Iconography and biblical studies. Proceedings of the iconography sessions at the Joint EABS/SBL Conference, 22-26 July 2007, Vienna, Austria. Münster: Ugarit-Verlag, 2009. (AOAT, 361).

HULSTER, Izaak de; STRAWN, Brent A.; BONFIGLIO, Ryan P. (eds.). [IEHBOT] Iconographic exegesis of the Hebrew Bible/Old Testament: an introduction to its method and practice. Göttingen: Vandenhoeck \& Ruprecht, 2015, p. 19-42. 
KEEL, Othmar. A Stamp Seal Research Project and a Group of Scarabs with Raised Relief. Akeadica, v. 49, p. 1-16, 1986a.

KEEL, Othmar. Antike Vorläufer der Engel: von den heidnischen Ahnen einiger jüdischerchristlicher Engel-Vorstellungen. In: FRANZL, Klaus P.; HAHN, Sylvia; HASSLBERGER, Bernhard; JOCHER, Norbert; KNOPP, Norbert (eds.). Engel. Mittler zwischen Himmel und Erde: im Diözenesanmuseum Freising 6. November 2010 bis 1. Mai 2011. Freising: Deutscher Kunstverlag, 2010a, p. 226-249.

KEEL, Othmar. Bibel und Ikonographie“. Kleine Geschichte des Themas mit ein paar Bemerkungen zur Methode. Bibel und Kirche, v. 40, n. 4 (Bibel und Ikonographie), p. 143-147, $1985 \mathrm{a}$.

KEEL, Othmar. Bildträger aus Palästina/Israel und die besondere Bedeutung der Miniaturkunst. In: KEEL, Othmar; SCHROER, Silvia. Studien zu den Stempelsiegeln aus Palästina/Israel. Freiburg; Göttingen: Universitätsverlag Freiburg; Vandenhoeck \& Ruprecht, 1985b, p. 7-47. (OBO, 67).

KEEL, Othmar. [CSAP] Corpus der Stempelsiegel-Amulette aus Palästina/Israel. Von den Anfängen bis zur Persezeit. 6 vols (Eiletung, I, II, III, IV, V). Freiburg; Göttingen: Universitätsverlag Freiburg; Vandenhoeck \& Ruprecht, 1995a, 1997a, 2010b, 2010c, 2013, 2017a. (OBO SA, $10,13,27,31,33,35)$.

KEEL, Othmar. Das Böcklein in der Milch seiner Mutter und verwandtes: In Lichte eines altorientalischen Bildmotivs. Freiburg; Göttingen: Universitätsverlag Freiburg; Vandenhoeck \& Ruprecht, 1980a (OBO, 33).

KEEL, Othmar. Das Hohelied. Zürich: TVZ, 1986b. (ZBK). [Ing. KEEL, Othmar. The Song of Songs. Minneapolis: Fortress Press, 1994c. (CC).]

KEEL, Othmar. Das Recht der Bilder gesehen zu werden: Drei Fallstudien zur methode der interpretation altorientalischer Bilder. Freiburg; Göttingen: Universitätsverlag Freiburg; Vandenhoeck \& Ruprecht, 1992a. (OBO, 122).

KEEL, Othmar. Deine Blicke sind Tauben: zur metaphorik des Hohen Liedes. Stuttgart: Verlag Katholisches Bibelwerk, 1984 (SBS, 114/115).

KEEL, Othmar. Die Geschichte Jerusalems und die Entstehung des Monotheismus (Orte und Landschaften der Bibel 4.1. Göttingen: Vandenhoeck \& Ruprecht), 2007a. [versão abreviada: KEEL, Othmar. Jerusalem und der eine Gott. Eine Religionsgeschichte. Göttingen: Vandenhoeck \& Ruprecht, 2014 / Ing.: KEEL, Othmar. Jerusalem and the One God: A Religious History.Minneapolis: Fortress Press, 2017b.]

KEEL, Othmar. Die kultischen Massnahmen Antiochus’ IV. In Jerusalem: Religionsverfolgung und/oder Reformversuch? Eine Skizze. In: KRAŠOVEC, Jože. (ed.). Interpretation of the Bible. The International Symposium in Slovenia. Sheffield: Sheffield Academic Press, 1998a, p. 217-42. (JSOTSup, 289).

KEEL, Othmar. Die Weisheit "spielt” vor Gott. Ein ikonographischer Beitrag zur Deutung des męsahäqät in Sir 8,30f. Freiburger Zeitschrift für Philosophie und Theologie, v. 21, p. 1-66, 1974a. KEEL, Othmar. [BS] Die Welt der altorientalischen Bildsymbolik und das Alte Testament. Am Beispiel der Psalmen. 5. ed. Zürich: Neukirchen, 1996. [KEEL, Othmar. The Symbolism of the Biblical World: Ancient Near Eastern Iconography and the Book of Psalms. Winona Lake: Eisenbrauns, 1997d] 
KEEL, Othmar. "Do meio das nações" a bíblia como porta de entrada de culturas antigas. Concilium, v. 1, p. 10-21, 1995b.

KEEL, Othmar. Feinde und Gottesleugner: studien zum image der Widersacher in den individualpsalmen. Stuttgart: Verlag Katholisches Bibelwerk, 1969. (SBM, 7).

KEEL, Othmar. Goddesses and trees, new moon, and Yahweh. Sheffield: Sheffield Academic, 1998b. (JSOTSup, 261).

KEEL, Othmar. Grundsätzliches und das Neumondemblem zwischen den Bäumen. BN, v. 6, p. 40-54, 1978a.

KEEL, Othmar. Iconography and the Bible. In: FREEDMAN, D. N. et al. (eds.). The $A n$ chor Yale Bible Dictionary. Vol. 3. New York: Doubleday, 1992b, p. 358-74.

KEEL, Othmar. Jahwes Entgegnung an Ijob: eine deutung von Ijob 38-41 vor dem Hintergrund der zeitgenössischen Bildkunst. Göttingen: Vandenhoeck \& Ruprecht, 1978b. (FRLANT 121).

KEEL, Othmar. Jahwe-visionen und siegelkunst. eine neue deutung der majestätsschilderungena in Jes 6, Ez 1 und 10 und Sach 4. Stuttgart: Verlag Katholisches Bibelwerk, 1977a. (SBS, $84 / 85)$.

KEEL, Othmar. Perspektiven der forschung. In: KEEL, Othmar; UEHLINGER, Christoph. Altorientaliscche miniaturkunst. die ältesten visuellen Massenkommunikationsmittel. Freiburg; Göttingen: Universitätsverlag Freiburg; Vandenhoeck \& Ruprecht, 1997c, p. 124-46.

KEEL, Othmar. Powerful symbols of victory, the parts stay the same, the actors change. JNSL, v. 25, n. 2, p. 205-40, 1999.

KEEL, Othmar. Ptah auf Siegelamuletten aus Palästina/Israel. Einige gesetzmässigkeiten bei der übernahme von Motiven der Grosskunst auf Miniaturbildträger. In: KIPPENBERG, H. G.; BOSCH, L. P. van den; LEERTOUWER, L.; WITTE, H. A. (eds.). Visible religion VII: genres in visual representation. Proceedings of a Conference held in 1986 by invitation of the Werner-Reimers-Stiftung in Bad Homburg (Federal Republic of Germany). Leiden; Nova Iorque; København; Köln: Brill, 1990, p. 199-232.

KEEL, Othmar. [SSPI IV] Studien zu den stempelsiegeln aus Palästina/Israel IV. Freiburg; Göttingen: Universitätsverlag Freiburg; Vandenhoeck \& Ruprecht, 1994b. (OBO, 135).

KEEL, Othmar. Vögel als boten: studien zu Ps 68, 12-14, Gen 8, 6-12, Koh 10,20 und dem Aussenden von Botenvögeln Ägypten. Freiburg; Göttingen: Universitätsverlag Freiburg; Vandenhoeck \& Ruprecht, 1977b. (OBO, 14).

KEEL, Othmar. Wirkmächtige Siegeszeichen im Alten Testament: ikonographisch studien zu Jos 8, 18-26; Ex 17, 8-13; 2 Kön 13, 14-19 und 1 Kön 22, 11. Freiburg; Göttingen: Universitätsverlag Freiburg; Vandenhoeck \& Ruprecht, 1974b. (OBO, 5).

KEEL, Othmar; KEEL-LEU, Hildi; SCHROER, Silvia. [SSPI II] Studien zu den stempelsiegeln aus Palästina/Israel II. Freiburg; Göttingen: Universitätsverlag Freiburg; Vandenhoeck \& Ruprecht, 1989. (OBO, 88).

KEEL, Othmar; SCHROER, Silvia. Creation: biblical theologies in the context of the ancient Near East. Trad. Peter T. Daniels. Winona Lake: Eisenbrauns, 2015.

KEEL, Othmar; SCHROER, Silvia. Eva: mutter alles lebendigen. Frauen- und göttinnenidole aus dem Alten Orient. Freiburg: Academic Press Fribourg Schweiz, 2004. 
KEEL, Othmar; SCHROER, Silvia. [SSPI I] Studien zu den stempelsiegeln aus Palästina/ Israel I. Freiburg; Göttingen: Universitätsverlag Freiburg; Vandenhoeck \& Ruprecht, 1985. (OBO, 67). KEEL, Othmar; SHUVAL, Menahem; UEHLINGER, Christoph. [SSPI III] Studien zu den stempelsiegeln aus Palästina/Israel III. Die Frühe Eisenzeit, Ein Workshop. Freiburg; Göttingen: Universitätsverlag Freiburg; Vandenhoeck \& Ruprecht, 1990. (OBO, 100).

KEEL, Othmar; UEHLINGER, Christoph. [GGG] Gods, Goddesses and images of God. Minneapolis: Fortress Press, 1998. [Al. KEEL, Othmar; UEHLINGER, Christoph. Göttinnen, Götter und Gottessymbole: Neue Erkenntnisse zur Religionsgeschichte Kanaans und Israel aufgrund bislang unerschossener ikonographischer Quellen. 6. ed. Freiburg im Bresgau: Herder, 2010. (QD, 34)].

KLEIN CARDOSO, Silas. Amuletos como mídia: poder estampado em ossos e o "Antigo Israel”. Caminhando, São Bernardo do Campo, v. 25, n. 1, p. 141-161, 2020a.

KLEIN CARDOSO, Silas. Culturas materiais e visuais das religiões do livro. O caso do “Antigo Israel”. In: MENDONÇA, Kátia M. L.; RENDERS, Helmut; HIGUET, Etienne A. (eds.). Religião e cultura visual no Brasil: desafios e métodos. Belém: Editora da UEPA, 2020b, p. 23-51. (Ciências da Religião, 1).

KLEIN CARDOSO, Silas. Exegese iconográfica da Bíblia Hebraica/Antigo Testamento: notas sobre o passado, passos para o futuro. Último Andar, v. 30, p. 105-118, 2017.

KLEIN CARDOSO, Silas. Redes mágico-míticas no alvorecer de Israel: "religião" no platô de Benjamim no Ferro I-IIA. 450 f. Tese (Doutorado, Ciências da Religião) - Universidade Metodista de São Paulo, 2019.

KLEIN CARDOSO, Silas. The Goddesses and Gods of Saul. Pistis \& Praxis, Curitiba, v. 12, n. 2, p. 352-370, 2020c.

KLINGBEIL, Martin G. Yabweh Fighting from Heaven: God as warrior and God of Heaven in the Hebrew Psalter and ancient Near Eastern iconography. Freiburg; Göttingen: Universitätsverlag Freiburg; Vandenhoeck \& Ruprecht: 1999. (OBO, 169).

KÜCHLER, Max. Schweigen, Schmuck und Schleier. Drei neutestamentliche Vorschriften zur Verdrängung der Frauen auf dem Hintergrund einer frauenfeindlichen exegese des Alten Testaments im antiken Judentum. Freiburg; Göttingen: Universitätsverlag Freiburg; Vandenhoeck \& Ruprecht, 1986. (NTOA, 1).

KÜCHLER, Max. Jerusalem. Ein Handbuch und Studienreiseführer zur Heiligen Stadt. Göttingen: Vandenhoeck \& Ruprecht, 2007. (OLB, 4.2).

LEVINE, Emily J. Dreamland of Humanists: Warburg, Cassirer, Panofsky, and the Hamburg School. Chicago: University of Chicago Press, 2013.

LEWIS, Theodore J. The origin and character of God: ancient Israelite religion through the lens of Divinity. New York: Oxford University Press, 2020.

LIPPKE, Florian. The southern Levant in context. A brief sketch of important features related to the religious symbol system in the Bronze Ages. In: MYNÁROVÁ, Jana. (ed.). Egypt and the Near East - the Crossroads. Proceedings of an International Conference on the Relations of Egypt and the Near East in the Bronze Age, Prague, September 1-3, 2010. Praga: Charles University in Prague, 2011, p. 211-233.

METZGER, Martin. Königsthron und Gottesthron: thronformen und throndarstellungen in Ägypten und im Vorderen Orient im dritten und zweiten Jahrtausend vor Christus und 
deren Bedeutung für das Verständnis von Aussagen über den Thron im Alten Testament. Kevelaer: Butzon \& Bercker, 1985.

NEUMANN-GORSOLKE. Ute. Wer ist der «Herr der Tiere»? Eine hermeneutische Problemanzeige. Neukirchen-Vluyn: Neukirchener Theologie, 2012. (BTS, 85).

PANOFSKY, Erwin. Significado nas artes visuais. Trad. Maria Clara F. Kneese e J. Guinsburg. São Paulo: Perspectiva, 2014. (Debates, 99).

PARSONS, Talcott. The social system. With a new preface by Bryan S. Turnner. London: Routledge, 1991 [1951].

PRITCHARD, James B. [ANEP] Ancient Near East Pictures in Images Relating to the Old Testament. 2. ed. com suplemento. Princeton: Princeton University Press, 1969a.

PRITCHARD, James B. [ANET] Ancient Near East Texts Relating to the Old Testament. 3. ed. com suplementos. Princeton: Princeton University Press, 1969b.

PROKOP, Daniel. The pillars of the First Temple (1Kgs 7,15-22): a study from ancient Near Eastern, biblical, archaeological, and iconographic perspectives. Tübingen: Mohr Siebeck, 2020. (FAT 2, 116).

ROGERSON, J. W. Old Testament. In: ROGERSON, J. W.; LIEU, Judith M. (eds.). The Oxford Handbook of Biblical Studies. Oxford: Oxford University Press, 2006, p. 5-26.

SASS, Benjamin; UEHLINGER, Christoph. Studies in the iconography of northwest semitic inscribed seals. Proceedings of a symposium held in Fribourg on April 17-20, 1991. Freiburg; Göttingen: Universitätsverlag Freiburg; Vandenhoeck \& Ruprecht, 1993. (OBO, 125).

SCHÄFER, Heinrich. Principles of egyptian art. Oxford: Oxford University Press, 2002.

SCHROER, Silvia. [IPIAO I-IV] Die ikonographie Palästinas/Israels und der Alte Orient: eine Religionsgeschichte in Bildern. 4 vols. Fribourg: Schwabe; Bibel+Orient Museum, 2005 [w/ KEEL, Othmar], 2008a, 2011, 2018.

SCHROER, Silvia. Gender and iconography from the viewpoint of a feminist biblical scholar. Lectio difficilior, n. 2, 2008b. Disponível em: http://www.lectio.unibe.ch/08_2/pdf/ Schroer_gender_and_iconography_2.pdf. Acesso em 12/02/2021.

SCHROER, Silvia. Ikonographie, biblische. In: GÖRG, Manfred; LANG, Bernhard (eds.). Neues Biblische Lexikon.Vol. 2. Zurich: Benziger, 1995, p. 219-226.

SCHROER, Silvia. In Israel gab es bilder: Nachrichten von darstellender Kunst im Alten Testament. Freiburg; Göttingen: Universitätsverlag Freiburg; Vandenhoeck \& Ruprecht, 1987b. (OBO, 74).

SCHROER, Silvia. Transformações da fé-documento de natureza intercultural na Bíblia. Concilium, v. 1, 1994, p. 8-21.

SCHROER, Silvia; STAUBLI, Thomas. Simbolismo do corpo na Bíblia. São Paulo: Paulinas, 2003.

SCHROER, Silvia; WYSSMANN, Patrick. The imagery of Palestine/Israel between East and West: a History of Religion based on pictures from the Persian to the Hellenistic Period. HeBAI, v. 8, p. 184-202, 2019.

SHILS, Edward. Tradition. Chicago: University of Chicago Press, 1981.

STAUBLI, Thomas. Cherubim, I. Ancient Near East and Hebrew Bible/Old Testament. In: ALLISON, Dale C. et al. (eds.). The Encyclopedia of the Bible and its Reception. Vol. 5. 2012, p. $55-58$. 
STAUBLI, Thomas; SCHROER, Silvia. Menschenbilder der Bibel. Ostfildern: Patmos Verlag, 2014.

STEIGER, Johann A. The development of the reformation legacy: hermeneutics and interpretation of the Sacred Scripture in the Age of Orthodoxy. In: SÆBØ, Magne (ed.). Hebrew Bible/Old Testament, the history of its interpretation. II: From the Renaissance to the Enlightment. Göttingen: Vandenhoeck \& Ruprecht, 2008, p. 691-757.

STRAWN, Brent A. What is Stronger than a Lion? Leonine image and metaphor in the Hebrew and the ancient Near East. Freiburg; Göttingen: Universitätsverlag; Vandenhoeck \& Ruprecht, 2005. (OBO, 212).

SOUZA, Mario M. Bíblia, imagem e memória. Uma abordagem iconológica dos aspectos político-religiosos no livro de Reis. 2019. 510 f. Tese (Doutoraado, Teologia) - Universidades EST, 2019.

THEISSEN, Gherd. Lokalkolorit und Zeitgeschichte in den Evangelien. Freiburg; Göttingen: Universitätsverlag Freiburg; Vandenhoeck \& Ruprecht, 1989. (NTOA, 8).

TOORN, Karel van der. Introduction. In: TOORN, Karel van der (ed.). The image and the Book: iconic cults, aniconism, and the rise of the Book Religion in Israel and the ancient Near East. Leuven: Peeters, 1997, p. 15-19. (CBET, 21).

TÖYRÄÄNVUORI, Joana. Psalm 29 and methodological triangulation: what can Ugarit parallels and iconographic motifs add to the interpretation of a Psalm. BN, v. 186, p. 51 $73,2020$.

UEHLINGER, Christoph. Approaches to visual culture and religion: disciplinary trajectories, interdisciplinary connections, and some suggestions for further progress. MTSR, v. 27, p. 384-422, 2015.

UEHLINGER, Christoph. Beyond "Image Ban" and "Aniconism": reconfiguring ancient Israelite and Early Jewish religion $\backslash s$ in a visual and material religion perspective. In: STORDALEN, Terje; MEYER, Birgit (eds.). Figuration and sensation of the unseen in Judaism, Christianity and Islam: contested desires. London: Bloomsbury, 2019a, p. 99-123. (BSMR).

UEHLINGER, Christoph. Bildquellen und "Geschichte Israels" Grundsätzliche Überlegungen und Fallbeispiele. In: HARDMEIER, Christof. (ed.). Steine, Bilder, Texte. Historische Evidenz außerbiblischer und biblischer Quellen. Leipzig: Evangelische Verlagsanstalt, 2001, p. 25-77. (ABG, 5).

UEHLINGER, Christoph. Companhias incômodas para Javé? Deusas no mundo do Antigo Israel e arredores. Mandrágora, v. 25, n. 1, 2019b, p. 5-31.

UEHLINGER, Christoph. O clamor da terra: perspectivas bíblicas para o tema ecologia e violência. Concilium, n. 5, p. 52-71, 1995.

UEHLINGER, Christoph. Das Buch und die Bilder: 25 Jahre ikonographischer Forschung am Biblischen Institut der Universität Freiburg Schweiz - Dank an Othmar Keel. In:

UEHLINGER, Christoph (ed.). Images as media: sources for the cultural history of the Near East and the Eastern Mediterranean (Ist Millennium BCE) Freiburg; Göttingen: Universitätsverlag Freiburg; Vandenhoeck \& Ruprecht, 2000, p. 399-408. (OBO, 175).

UEHLINGER, Christoph. Neither eyewitnesses, nor windows to the Past, but valuable testimony in its own Right. Remarks on iconography, source criticism and ancient dataprocessing. In: WILLIAMSON, H. G. (ed.). Understanding the history of ancient Israel. London: British Academy, 2007, p. 173-228. (PBA, 143). 
WEISSENRIEDER, Annette; WENDT, Friederike. Images as comunication. The methods of iconography. In: WEISSENRIEDER, Annette; WENDT, Friederike; GEMÜNDEN, Petra von (eds.). Picturing the New Testament. Tübingen: Mohr Siebeck, 2005, p. 3-49. (WUNT, 2).

WEISSENRIEDER, Annette; WENDT, Friederike; GEMÜNDEN, Petra von (eds.). Picturing the New Testament. Tübingen: Mohr Siebeck, 2005. (WUNT, 2).

WINTER, Urs. Frau und Göttin. Exegetische und ikonographische studien zum weiblichen Gottesbild im Alten Israel und in dessen Umwelt. 2. ed. Freiburg; Göttingen: Universitätsverlag Freiburg; Vandenhoeck \& Ruprecht, 1987. (OBO, 53). 